\title{
Esophageal Nocturnal Baseline Impedance and Post-reflux Swallow-induced Peristaltic Wave Index in Identifying Proton Pump Inhibitor-refractory Non-erosive Reflux Disease
}

\author{
Yan Wang, Bixing Ye, Meifeng Wang, Lin Lin, and Liuqin Jiang* \\ Department of Gastroenterology, The First Affiliated Hospital of Nanjing Medical University, Nanjing, Jiangsu, China
}

\section{Background/Aims}

Esophageal mean nocturnal baseline impedance (MNBI) levels and post-reflux swallow-induced peristaltic wave (PSPW) index could increase the diagnostic value of 24-hour multichannel intraluminal impedance and $\mathrm{pH}$ monitoring in patients with gastroesophageal reflux disease. This study aims to compare the MNBI and PSPW index in patients with no evidence of erosive reflux disease.

\section{Methods}

Impedance-pH monitoring tracings from 70 patients, 50 with non-erosive reflux disease (NERD) and 20 with functional heartburn (FH), were reviewed. According to proton pump inhibitors (PPI) treatment response, NERD patients were divided into NERD/PPI responders and NERD/PPI nonresponders. MNBI, PSPW index, and intercellular spaces were measured and compared among each group.

\section{Results}

MNBI values and PSPW index were lower in NERD patients than in $\mathrm{FH}(P<0.01$ and $P<0.05$, respectively). MNBI positively correlated with PSPW index $(r=0.525, P<0.001)$. NERD/PPI responders had lower MNBI values and PSPW index compared to NERD/PPI nonresponders (both $P<0.01$ ). MNBI and PSPW index distinguished NERD from FH patients with an area under the curve of 0.914 and 0.677 , respectively. Wider intercellular space could be identified in patients with NERD $(P<0.01)$.

\section{Conclusion}

MNBI and PSPW index may differentiate NERD from FH patients and relate to PPI treatment efficacy in patients with NERD.

(J Neurogastroenterol Motil 2021;27:525-532)

\section{Key Words}

Electric impedance; Gastroesophageal reflux; Intercellular spaces; Proton pump inhibitors

Received: April 13, 2020 Revised: April 15, 2021 Accepted: April 15, 2021

(.) This is an Open Access article distributed under the terms of the Creative Commons Attribution Non-Commercial License (http://creativecommons. org/licenses/by-nc/4.0) which permits unrestricted non-commercial use, distribution, and reproduction in any medium, provided the original work is properly cited.

*Correspondence: Liuqin Jiang, MD Department of Gastroenterology, The First Affiliated Hospital of Nanjing Medical University, 300\# Guangzhou Road, Gulou District, Nanjing 210029, China

Tel: +86-025-68303472, Fax: +86-13951017379, E-mail: jiangliuqin@163.com

Yan Wang and Bixing Ye contributed equally to this work. 


\section{Introduction}

Among patients with typical gastroesophageal reflux disease (GERD) symptoms, non-erosive reflux disease (NERD) patients with no evidence of esophageal injury under endoscopy account for the majority. ${ }^{1,2}$ Patients with heartburn symptoms are heterogeneous, some of which are functional heartburns $(\mathrm{FH}){ }^{3}$ Patients with $\mathrm{FH}$ assessed using impedance-pH monitoring have normal esophageal acid exposure and normal symptom association analysis. The diagnosis of $\mathrm{FH}$ needs to be considered when patients have no visible esophageal mucosal damage at routine endoscopy. Proton pump inhibitors (PPIs) are used extensively for the treatment of GERD, but a large number of patients have persistent symptoms despite PPI therapy, ${ }^{5}$ especially patients with NERD. ${ }^{6,7}$ The underlying mechanisms accounting for PPI failure in NERD patients have been a focused issue.

Multichannel intraluminal impedance and $\mathrm{pH}$ monitoring (MII-pH monitoring) detects reflux episodes including acid reflux, weakly acid reflux, and alkaline reflux. ${ }^{8,9}$ Recently, besides the traditional reflux events and acid exposure time, several novel multichannel intraluminal impedance and $\mathrm{pH}(\mathrm{MII}-\mathrm{pH})$ metrics have been proposed. Baseline impedance reflects the electrical conductivity and mucosal integrity of the esophageal wall. ${ }^{10}$ Previous studies revealed that mean nocturnal baseline impedance (MNBI) correlated with esophageal histopathologic changes and was lower in GERD patients than in FH patients and healthy subjects. ${ }^{11,12}$ Post-reflux swallow-induced peristaltic wave (PSPW) index could be used to assess the impaired chemical clearance in patients with GERD, which is significantly lower in NERD patients than $\mathrm{FH}$ patients. ${ }^{13}$ It was demonstrated that PSPW index and MNBI increased the diagnostic accuracy of MII-pH monitoring in cases with PPI responsive heartburn. ${ }^{14}$ Frazzoni et $\mathrm{al}^{15}$ found that $76.0 \%$ and 92.0\% of PPI-responsive heartburn cases had abnormal MNBI and PSPW index. However, Ribolsi et $\mathrm{al}^{16}$ found no difference of MNBI between PPI responders and nonresponders in NERD patients and that baseline impedance could not predict PPI response in NERD patients. So far, the role of PSPW index and MNBI in PPI-refractory NERD patients has not been investigated well.

We compared MNBI, PSPW index, intercellular spaces, and pathophysiological characteristics among PPI responsive NERD patients, PPI non-responsive NERD patients and $\mathrm{FH}$ patients. We also evaluated the efficacy of MNBI and PSPW index in discriminating NERD from FH patients and NERD/PPI responders from NERD/PPI nonresponders. This study aims to evaluate the effect of measuring MNBI and PSPW index in identifying PPI-refractory NERD patients.

\section{Materials and Methods}

\section{Study Subjects}

We analyzed consecutive subjects referred to our outpatient clinics between Jan 2014 and Jan 2018 whose endoscopic testing showed no evidence of erosion within 1 week before undergoing MII-pH monitoring. Patients over 18 years old with symptoms of heartburn and/or regurgitation persisting for more than 6 months and score of validated Reflux Disease Questionnaire no less than 12 were included. ${ }^{17}$ NERD patients were treated with rabeprazole or omeprazole $20 \mathrm{mg}$ per day for at least 8 weeks. They were considered as NERD/PPI nonresponders when the improvement of symptom score was less than $50.0 \%{ }^{18}$ while classified as NERD/ PPI responders if improvement $\geq 50.0 \%$. Patients were excluded if they had peptic stricture or ulcer, history of tumor or surgery, and severe esophageal motility disorders. The Ethical Committee of the hospital approved this study (IRB No. 2014-SR-010). All subjects gave standard informed written consent before commencement of this study.

\section{Esophageal Multichannel Intraluminal Impedance and $\mathrm{pH}$ Monitoring}

Subjects were asked to stop PPIs or prokinetic drug medication at least 2 weeks before the MII-pH monitoring. The MII-pH catheter (Given Imaging) was positioned by an experienced nurse and then inserted into the esophagus and taped to the face. The $\mathrm{pH}$ sensor was located at $5 \mathrm{~cm}$ proximal to lower esophageal sphincter (LES) and the $z 1$ to z6 impedance probes were at 17, 15, 9, 7, 5, and $3 \mathrm{~cm}$ proximal to the $\mathrm{LES}$, respectively. ${ }^{19}$ All subjects were instructed to record the activities, symptoms, meals, and time of the supine posture during the 24 hours of measurement.

\section{Multichannel Intraluminal Impedance and pH Data Analysis}

We measured and calculated the following variables: (1) numbers and types of reflux episodes; ${ }^{20}$ (2) DeMeester score; (3) acid exposure time (AET); (4) MNBI values; and (5) PSPW index. Reflux episodes were divided into acidic $(\mathrm{pH}<4.0)$, weakly acidic ( $\mathrm{pH} 4.0-7.0)$, and weakly alkaline $(\mathrm{pH}>7.0)$ refluxes. ${ }^{21}$ AET was calculated as the time of $\mathrm{pH}$ below 4 at the distal esophagus, divided by the total time of testing. Patients were classified as NERD if 
Table 1. Baseline Characteristics of Patients With Non-erosive Reflux Disease and Functional Heartburn

\begin{tabular}{lcccc}
\hline \multicolumn{1}{c}{ Characteristics } & $\begin{array}{c}\text { Total NERD } \\
(\mathrm{n}=50)\end{array}$ & $\begin{array}{c}\text { FH } \\
(\mathrm{n}=20)\end{array}$ & $\begin{array}{c}\text { NERD/PPI responders } \\
(\mathrm{n}=25)\end{array}$ & $\begin{array}{c}\text { NERD/PPI nonre- } \\
\text { sponders }(\mathrm{n}=25)\end{array}$ \\
\hline Age $(\mathrm{yr})$ & $51.6 \pm 14.0$ & $56.3 \pm 13.1$ & $53.2 \pm 12.9$ & $50.1 \pm 15.1$ \\
Male & $27(54)$ & $9(45)$ & $14(56)$ & $13(52)$ \\
DeMeester score & $19.9 \pm 11.9$ & $6.0 \pm 4.7^{\mathrm{a}}$ & $24.0 \pm 6.2$ & $15.7 \pm 14.7^{\mathrm{b}}$ \\
AET (\%) & $5.7 \pm 3.4$ & $1.7 \pm 1.3^{\mathrm{a}}$ & $6.9 \pm 1.8$ & $4.5 \pm 4.2^{\mathrm{b}}$ \\
Acid refluxes & $77.5(44.3,113.5)$ & $20.0(6.0,39.0)^{\mathrm{a}}$ & $100.0(67.5,146.0)$ & $63.0(28.0,83.0)^{\mathrm{b}}$ \\
Weakly acid refluxes & $19.0(10.0,37.3)$ & $10.5(6.0,12.0)^{\mathrm{a}}$ & $13.0(5.0,26.0)$ & $26.0(15.0,54.0)^{\mathrm{c}}$ \\
Weakly alkaline refluxes & $2.0(1.0,5.8)$ & $0(0,0)^{\mathrm{a}}$ & $1.0(1.0,3.0)$ & $3.0(1.5,13.0)$ \\
Long term acid (> min) & $3.0(1.0,5.0)$ & $1.0(0,1.5)^{\mathrm{a}}$ & $4.0(2.0,7.0)$ & $1.0(1.0,5.0)^{\mathrm{b}}$ \\
\hline
\end{tabular}

NERD, non-erosive reflux disease; FH, functional heartburn; PPI, proton pump inhibitor; AET, acid exposure time.

${ }^{a} P$-value $<0.001$ compared with total NERD.

${ }^{\mathrm{b}} P$-value $<0.05$ compared with NERD/PPI responders.

${ }^{c} P$-value $<0.01$ compared with NERD/PPI responders.

Data are presented as mean \pm standard deviation, $\mathrm{n}(\%)$, or median (interquartile range: 25 th, 75 th).

AET $>4.0 \%$ and/or reflux episodes $>80$, while $\mathrm{FH}$ was defined by normal AET, reflux episodes, and symptom association analysis. ${ }^{3}$

Baseline impedance levels were assessed blindly by 1 investigator who was unaware of the diagnostic results at three 10-minute time periods around $1 \mathrm{AM}, 2 \mathrm{AM}$, and $3 \mathrm{AM}$, which were not close to any periods of swallows, refluxes, and $\mathrm{pH} \mathrm{drops}^{22} \mathrm{MNBI}$ was the average value of 3 appropriate baseline impedance levels from each time period. MNBI from the impedance channel z5 was chosen for analysis, at which the $\mathrm{pH}$ sensor located to ensure that MNBI were obtained when $\mathrm{pH}>6 .^{23}$ The definition of PSPW was an antegrade $50.0 \%$ drop occurring within 30 seconds after a reflux event, originating from the most proximal impedance channel to all remaining distal impedance channels, and followed by at least $50.0 \%$ return to the baseline. The PSPW index was measured when dividing the number of PSPWs by the total reflux events. ${ }^{13}$

\section{Transmission Electron Microscopy Examination}

The biopsy specimens from endoscopy were obtained at the site within $3 \mathrm{~cm}$ proximal to the esophagogastric junction. ${ }^{24}$ The samples were fixed in a $2.5 \%$ glutaraldehyde solution at $4{ }^{\circ} \mathrm{C}$ and then post-fixed in $1.0 \%$ osmium tetroxide, infiltrated in Epon's resin, embedded and sectioned into ultra-thin slices. ${ }^{10}$ The specimens were observed and photographed under transmission electron microscopy (Hitachi, Tokyo, Japan). Intercellular spaces of the esophageal epithelial cells were evaluated using image analyzing system (Leica, Wetzlar, Germany). Ten pictures were obtained from each slice. Each image contained an intact cell and the vertical distance between the intact cell and its neighboring cells in 10 random directions was used to evaluate the intercellular space. In total, 100 intercellular spaces from 10 images were marked. The average value of intercellular space was calculated by an investigator who was unaware of the endoscopy and MII-pH findings.

\section{Statistical Methods}

Continuous parameters were presented as mean \pm standard deviation or median (interquartile range: 25 th, 75 th). Data were compared using unpaired Student's $t$ test if found to follow a normal distribution and Mann-Whitney $U$ test if not. Categorical data were presented as frequencies and proportions and compared using the chi-square test or Fisher's exact test. The correlation between MNBI and AET as well as PSPW index were investigated using Pearson's correlation statistics. The predictive values of MNBI, PSPW index and AET distinguishing NERD from FH patients were estimated using receiver operating characteristic (ROC) curves. Differences were considered statistically significant when $P$ value $<0.05$.

\section{Results}

\section{Patient Characteristics}

In total, we enrolled $50 \mathrm{NERD}$ patients, including $25 \mathrm{NERD} /$ PPI responders and 25 NERD/PPI nonresponders, and 20 $\mathrm{FH}$ patients. Patient demographic and clinical characteristics are reported in Table 1. Compared to patients with FH, the AET, DeMeester score, and reflux events were significantly higher in the NERD group. On the basis of response to PPI, the AET, DeMeester score, and episodes of acid, weakly acid, long term acid reflux ( $>5$ minutes) were higher in NERD/PPI responders than in NERD/PPI nonresponders, while episodes of weakly alkaline 

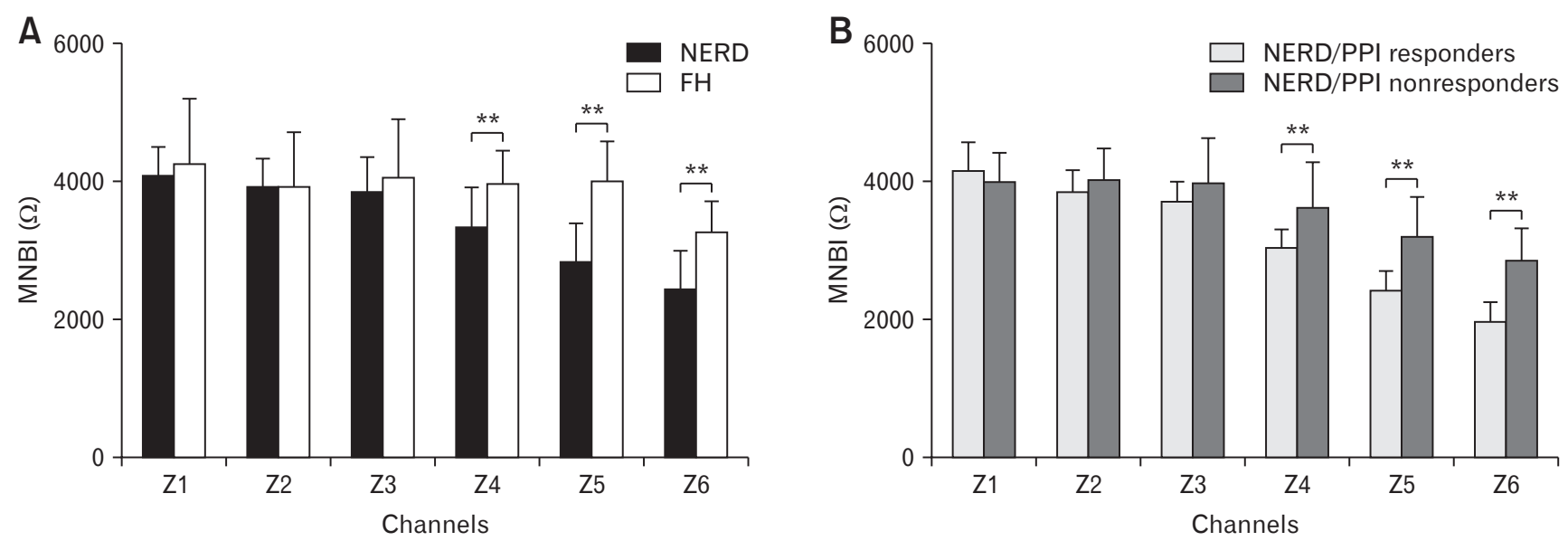

Figure 1. Mean nocturnal baseline impedance (MNBI) levels from each impedance channel in: (A) non-erosive reflux disease (NERD) and functional heartburn $(\mathrm{FH})$ patients and $(\mathrm{B}) \mathrm{NERD} /$ proton pump inhibitor $(\mathrm{PPI})$ responders and NERD/PPI nonresponders. ${ }^{* *} \mathrm{P}<0.01$.
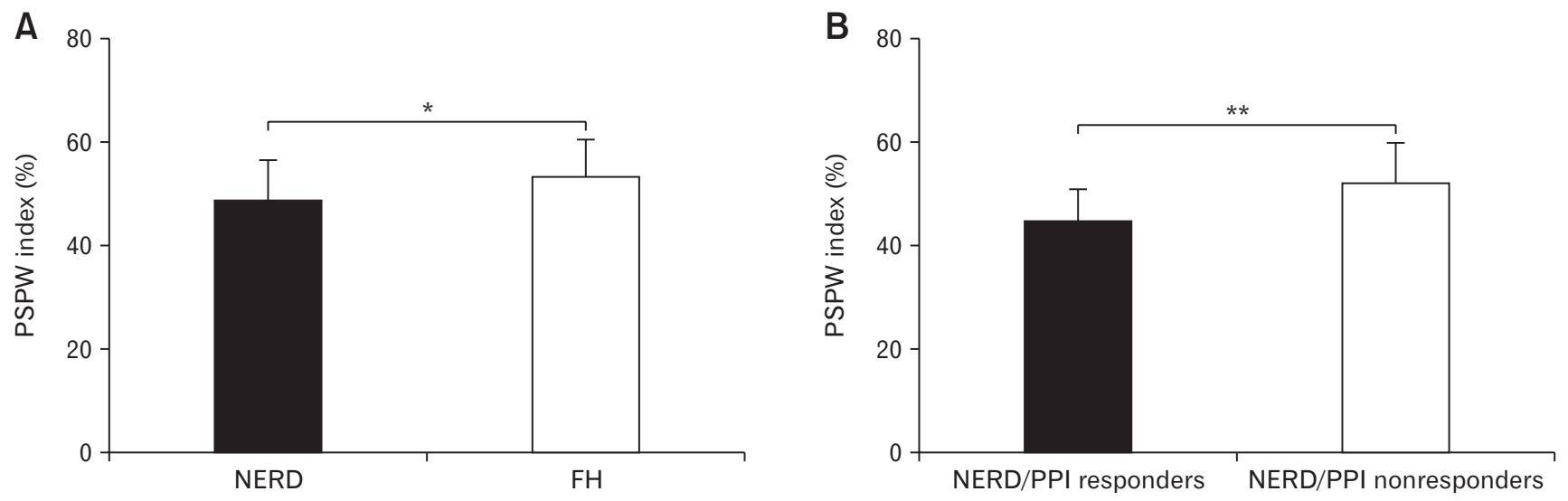

Figure 2. Comparison of post-reflux swallow-induced peristaltic wave (PSPW) index between: (A) non-erosive reflux disease (NERD) and functional heartburn $(\mathrm{FH})$ patients and $(\mathrm{B}) \mathrm{NERD} /$ proton pump inhibitor $(\mathrm{PPI})$ responders and NERD/PPI nonresponders. ${ }^{*} P<0.05,{ }^{* *} P<0.01$.
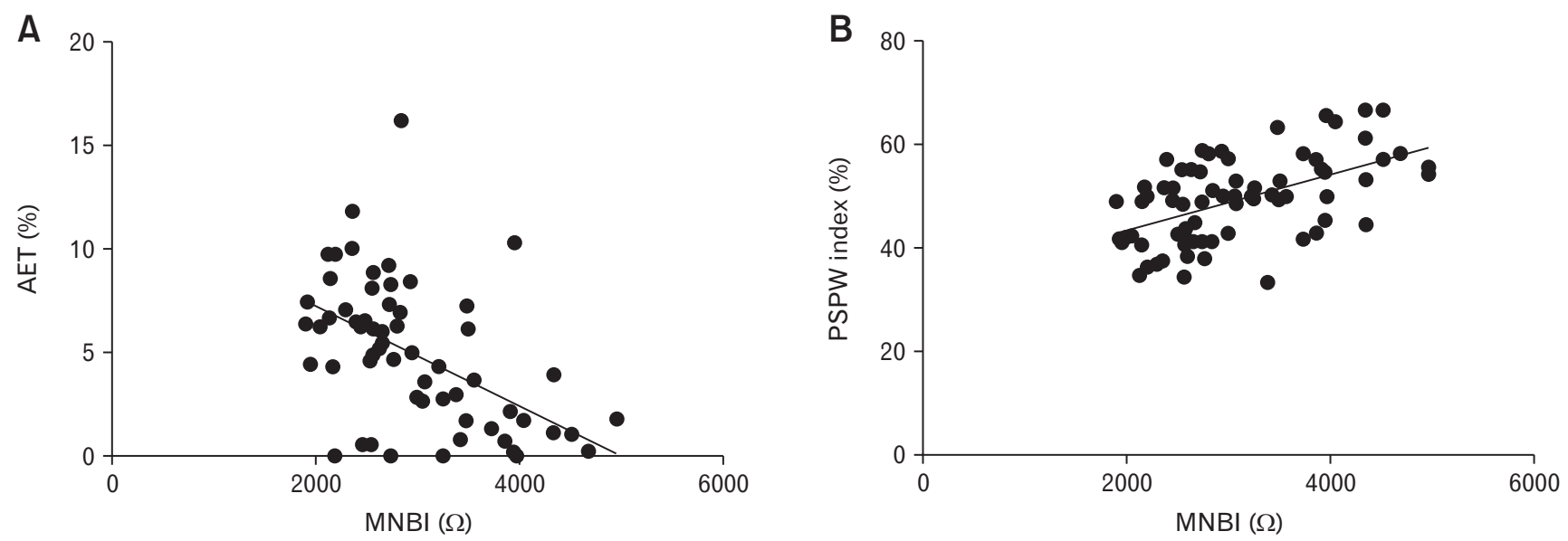

Figure 3. Correlation between mean nocturnal baseline impedance (MNBI) levels (z5) and: (A) acid exposure time (AET), (B) post-reflux swallow-induced peristaltic wave (PSPW) index. AET, acid exposure time. 
reflux demonstrated no significant differences between them.

\section{Mean Nocturnal Baseline Impedance and Post- reflux Swallow-induced Peristaltic Wave Analysis}

MNBI values from each channel across groups are shown in Figure 1. MNBI from z4, z5, and z6 in total NERD patients were significantly lower compared to $\mathrm{FH}$ patients $(3299.8 \pm 605.7$ vs $3926.5 \pm 511.0 \Omega, P<0.001 ; 2782.8 \pm 606.9$ vs $3974.0 \pm$ $598.4 \Omega, P<0.001 ; 2384.9 \pm 602.6$ vs $3232.9 \pm 469.9 \Omega, P<$ 0.001 , respectively). Similarly, the lower MNBI values from $z 4$ to z6 in NERD/PPI responders were observed compared to NERD/ PPI nonresponders $(3005.6 \pm 302.9$ vs $3594.1 \pm 690.5 \Omega, P<$ $0.001 ; 2394.0 \pm 293.2$ vs $3171.5 \pm 592.6 \Omega, P<0.001 ; 1940.0 \pm$ 294.4 vs $2829.8 \pm 492.3 \Omega, P<0.001$, respectively).

PSPW index was significantly lower in the total NERD group

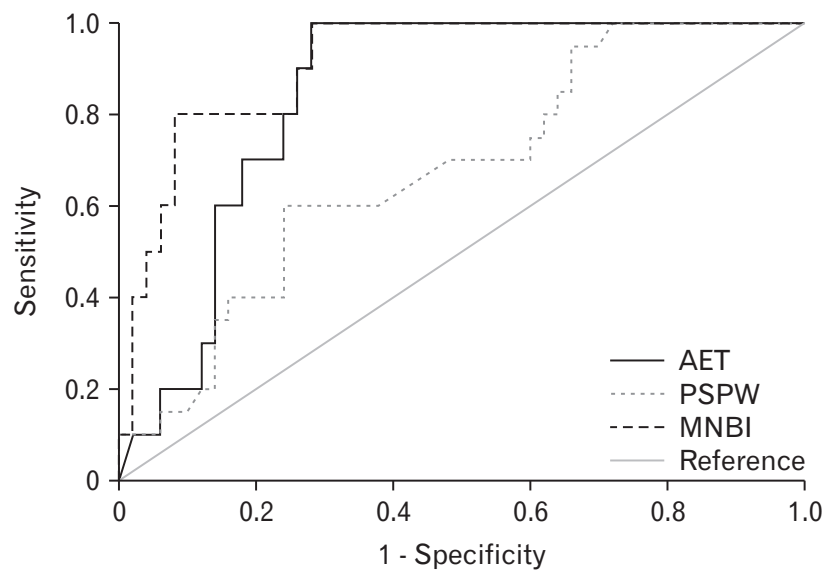

Figure 4. Receiver operating characteristic (ROC) curves for distinguishing functional heartburn $(\mathrm{FH})$ from non-erosive reflux disease (NERD) patients. AET, acid exposure time; PSPW, post-reflux swallow-induced peristaltic wave; MNBI, mean nocturnal baseline impedance.
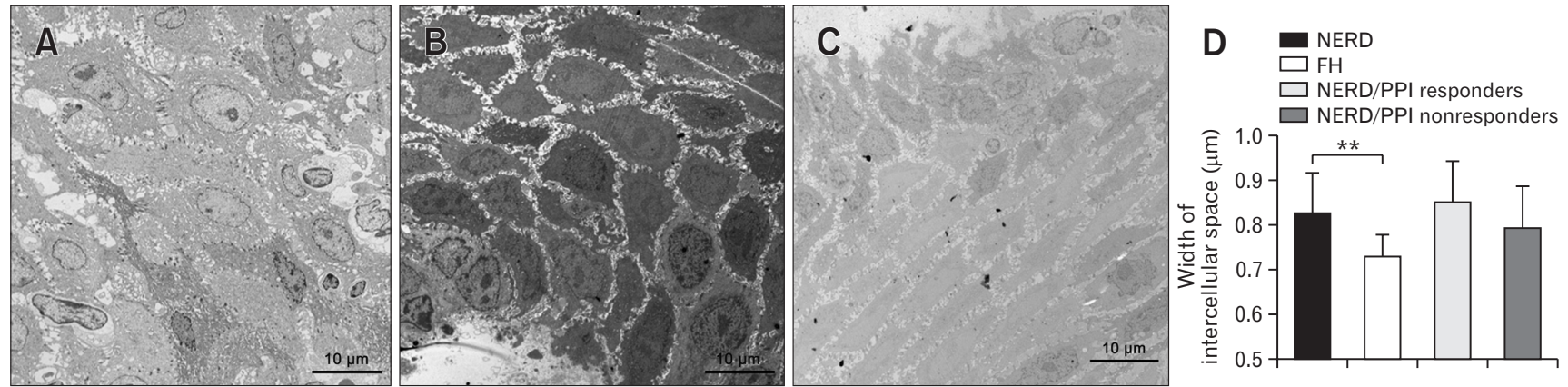

Figure 5. Comparison of the width of intercellular space among (A) functional heartburn (FH), (B) non-erosive reflux disease (NERD)/proton pump inhibitor (PPI) responders, (C) NERD/PPI non responders, and width of intercellular spaces in all groups (D). ${ }^{* *} P<0.01$. 
ers from NERD PPI/nonresponders. AET, PSPW index, and MNBI yielded AUC of $0.727,0.774$, and 0.893 with cutoff values of $4.4 \%, 49.1 \%$, and $2729.3 \Omega(P=0.006, P=0.001, P<0.001$, respectively). The sensitivity, specificity, positive and negative predictive values for evaluating PPI response in NERD patients were as follows: AET, $60.0 \%, 96.0 \%, 94.0 \%$, and $71.0 \%$; PSPW index, $80.0 \%, 76.0 \%, 77.0 \%$, and $79.0 \%$; MNBI, $80.0 \%, 92.0 \%, 91.0 \%$, and $82.0 \%$ respectively.

\section{Intercellular Spaces in the Esophageal Epithelium of Patients}

All patients showed ultrastructural integrity of the esophageal epithelial cells. The width of intercellular spaces of the NERD group were greater than that of $\mathrm{FH}$ (NERD vs FH: $0.82 \pm 0.02 \mu \mathrm{m}$ vs $0.73 \pm 0.02 \mu \mathrm{m}, P=0.005)$, but there was no difference between NERD/PPI responders and nonresponders $(0.85 \pm 0.03 \mu \mathrm{m}$ vs $0.80 \pm 0.03 \mu \mathrm{m}, P=0.108$ ) (Fig. 5).

\section{Discussion}

In this study, we investigated the clinical value of MNBI and PSPW index in patients with NERD and FH. We demonstrated that MNBI correlated to acid exposure and chemical clearance. Specifically, we determined that MNBI and PSPW index could discriminate between NERD and FH patients as well as NERD/ PPI responders and NERD/PPI nonresponders.

Currently, MII-pH monitoring is frequently used to estimate whether pathologic reflux exists and whether symptoms are associated with reflux events in patients with negative endoscopic results. Novel impedance metrics including PSPW index and MNBI have been proposed to evaluate esophageal chemical clearance and mucosal integrity. Kandulski et $\mathrm{al}^{11}$ demonstrated that distal baseline impedance could distinguish GERD from $\mathrm{FH}$ patients with the cutoff value, sensitivity, and specificity of $2100 \Omega, 78.0 \%$, and $71.0 \%$, respectively. Furthermore, Xie et $\mathrm{al}^{24}$ reported $1764 \Omega$ as the cutoff value of baseline impedance to differentiate patients with GERD from healthy subjects with $55.4 \%$ sensitivity and $100.0 \%$ specificity in the Chinese population. The cutoff value of MNBI to separate NERD from FH patients in our study is $3562 \Omega$, which is a high level compared to previous study. This is probably because we chose metrics from the channel located $5 \mathrm{~cm}$ above the LES to perform ROC analysis and we did not include patients who had erosive reflux disease in this study. MNBI reflects esophageal mucosal integrity ${ }^{25}$ and PSPW could be elicited by both acidic and weakly acidic refluxes. ${ }^{13}$ In this study, both MNBI and PSPW index could separate NERD from FH patients, and MNBI may be more efficient than PSPW index. Considering the day-to-day variability presented by $\mathrm{AET}^{26} \mathrm{MNBI}$ and PSPW index may be reliable parameters to distinguish GERD phenotypes when conventional MII-pH metrics afford ambiguous results.

We found that MNBI and PSPW index were also associated with PPI response in patients with NERD. NERD/PPI responders showed lower MNBI levels and PSPW index than NERD/ PPI nonresponders. At ROC analysis, both metrics showed high efficacy in differentiating between NERD/PPI responders and nonresponders. This was supported by the finding that the acid exposure was more severe in PPI responsive NERD patients. Previously, MNBI and PSPW index linked reflux with PPI-effectiveness better than $\mathrm{AET}^{27}$ Low PSPW index reflects impairment of chemical clearance and implies prolonged contact of mucosa with refluxes, which further leads to esophageal mucosal damage despite adequate acid suppression. ${ }^{13,28}$ Given the fact that patients with NERD respond less favorably to PPIs, MNBI, and PSPW index may be ideal markers to predict the efficacy of PPI in NERD patients.

GERD results from acid exposure, which affects mucosal integrity and further results in dilated intercellular spaces (DIS) and increased paracellular permeability in the epithelium. ${ }^{10} \mathrm{~A}$ previous study suggested that DIS may occur even when no visible mucosal damage could be observed at endoscopy ${ }^{29}$ and is typically present in patients with NERD.$^{10}$ We showed that the width of intercellular spaces of the NERD group were greater than that of $\mathrm{FH}$, indicating that DIS has the potential to segregate NERD from FH. We found no difference of the dilation of intercellular spaces between NERD PPI/responders and NERD PPI/nonresponders, which is consistent with a previous report. ${ }^{24}$ This is probably because DIS also results from inflammation other than acid exposure.

One of the limitations in this study is that we lack healthy subjects as a control group, which limits the association of MNBI and PSPW index with specific symptoms and endoscopic characteristics. Furthermore, we did not include patients with reflux hypersensitivity. We aimed to explore the relationship between MNBI or PSPW and pathological reflux in this study. Gao et al ${ }^{30}$ found that patients with reflux hypersensitivity showed lower PSPW index and MNBI values than $\mathrm{FH}$ patients and healthy volunteers. The immune reaction induced by the visceral hypersensitivity may cause DIS in patients without mucosal erosion. In fact, the inclusion of patients with hypersensitive esophagus would be helpful to explore the role of MNBI and PSPW index in different phenotypes of endoscopy-negative patients. In addition, the retrospective review of 
impedance-pH tracings may lead to misclassification of endoscopy negative patients if some did not stop PPI before the endoscopy.

In summary, this study evaluated the clinical utility of MNBI and PSPW index in patients with negative endoscopy. MNBI and PSPW index resulted to be useful in identifying patients with NERD from patients with FH. In addition, the efficacy of MNBI and PSPW index to identify PPI responsive NERD patients is acceptable. MNBI and PSPW index may be a promising metric to guide diagnosis and management in patients with NERD.

\section{Financial support: None.}

\section{Conflicts of interest: None.}

Author contributions: Yan Wang, Bixing Ye, Lin Lin, and Linqin Jiang conceived and designed the experiments; Bixing Ye, Linqin Jiang, and Meifeng Wang performed the experiments; Yan Wang, Bixing Ye, and Linqin Jiang analyzed the data; and Yan Wang and Liuqin Jiang wrote the manuscript.

\section{References}

1. Ronkainen J, Aro P, Storskrubb T, et al. High prevalence of gastroesophageal reflux symptoms and esophagitis with or without symptoms in the general adult Swedish population: a Kalixanda study report. Scand J Gastroenterol 2005;40:275-285.

2. Goh KL. Gastroesophageal reflux disease in Asia: a historical perspective and present challenges. J Gastroenterol Hepatol 2011;26(suppl 1):2-10.

3. Hachem C, Shaheen NJ. Diagnosis and management of functional heartburn. Am J Gastroenterol 2016;111:53-61.

4. Lee YY, Wu JCY. Management of patients with functional heartburn. Gastroenterology 2018;154:2018-2021, e1.

5. Fass R, Sifrim D. Management of heartburn not responding to proton pump inhibitors. Gut 2009;58:295-309.

6. Dean BB, Gano AD Jr, Knight K, Ofman JJ, Fass R. Effectiveness of proton pump inhibitors in nonerosive reflux disease. Clin Gastroenterol Hepatol 2004;2:656-664.

7. Bytzer P, van Zanten SV, Mattsson H, Wernersson B. Partial symptomresponse to proton pump inhibitors in patients with non-erosive reflux disease or reflux oesophagitis - a post hoc analysis of 5796 patients. Aliment Pharmacol Ther 2012;36:635-643.

8. Shay S, Tutuian R, Sifrim D, et al. Twenty-four hour ambulatory simultaneous impedance and $\mathrm{pH}$ monitoring: a multicenter report of normal values from 60 healthy volunteers. Am J Gastroenterol 2004;99:10371043.

9. Bredenoord AJ, Tutuian R, Smout AJ, Castell DO. Technology review: esophageal impedance monitoring. Am J Gastroenterol 2007;102:187194.

10. Farré R, Blondeau K, Clement D, et al. Evaluation of oesophageal mucosa integrity by the intraluminal impedance technique. Gut 2011;60:885-
892.

11. Kandulski A, Weigt J, Caro C, Jechorek D, Wex T, Malfertheiner P. Esophageal intraluminal baseline impedance differentiates gastroesophageal reflux disease from functional heartburn. Clin Gastroenterol Hepatol 2015;13:1075-1081.

12. Zhong C, Duan L, Wang K, et al. Esophageal intraluminal baseline impedance is associated with severity of acid reflux and epithelial structural abnormalities in patients with gastroesophageal reflux disease. J Gastroenterol 2013;48:601-610.

13. Frazzoni M, Manta R, Mirante VG, Conigliaro R, Frazzoni L, Melotti $\mathrm{G}$. Esophageal chemical clearance is impaired in gastro-esophageal reflux disease--a 24-h impedance-pH monitoring assessment. Neurogastroenterol Motil 2013;25:399-406, e295.

14. Frazzoni M, Savarino E, de Bortoli N, et al. Analyses of the post-reflux swallow-induced peristaltic wave index and nocturnal baseline impedance parameters increase the diagnostic yield of ompedance- $\mathrm{pH}$ monitoring of patients with reflux disease. Clin Gastroenterol Hepatol 2016;14:40-46.

15. Frazzoni L, Frazzoni M, de Bortoli N, et al. Postreflux swallow-induced peristaltic wave index and nocturnal baseline impedance can link PPIresponsive heartburn to reflux better than acid exposure time. Neurogastroenterol Motil 2017;29:e13116.

16. Ribolsi M, Emerenziani S, Borrelli O, et al. Impedance baseline and reflux perception in responder and non-responder non-erosive reflux disease patients. Scand J Gastroenterol 2012;47:1266-1273.

17. Shaw MJ, Talley NJ, Beebe TJ, et al. Initial validation of a diagnostic questionnaire for gastroesophageal reflux disease. Am J Gastroenterol 2001;96:52-57.

18. Sifrim D, Zerbib F. Diagnosis and management of patients with reflux symptoms refractory to proton pump inhibitors. Gut 2012;61:13401354.

19. Jiang L, Ye B, Wang Y, Wang M, Lin L. Esophageal body motility for clinical assessment in patients with refractory gastroesophageal reflux symptoms. J Neurogastroenterol Motil 2017;23:64-71.

20. Cho YK. How to interpret esophageal impedance $\mathrm{pH}$ monitoring. J Neurogastroenterol Motil 2010;16:327-330.

21. Vaezi MF, Sifrim D. Assessing old and new diagnostic tests for gastroesophageal reflux disease. Gastroenterology 2018;154:289-301.

22. Martinucci I, de Bortoli N, Savarino E, et al. Esophageal baseline impedance levels in patients with pathophysiological characteristics of functional heartburn. Neurogastroenterol Motil 2014;26:546-555.

23. Kohata Y, Fujiwara Y, Yamagami H, et al. Usefulness of baseline impedance in patients with proton pump inhibitor-refractory nonerosive reflux disease. J Gastroenterol Hepatol 2015;30(suppl 1):36-40.

24. Xie C, Sifrim D, Li Y, Chen M, Xiao Y. Esophageal baseline impedance reflects mucosal integrity and predicts symptomatic outcome with proton pump inhibitor treatment. J Neurogastroenterol Motil 2018;24:43-50.

25. Woodland P, Al-Zinaty M, Yazaki E, Sifrim D. In vivo evaluation of acid-induced changes in oesophageal mucosa integrity and sensitivity in non-erosive reflux disease. Gut 2013;62:1256-1261.

26. Penagini R, Sweis R, Mauro A, Domingues G, Vales A, Sifrim D. Inconsistency in the diagnosis of functional heartburn: usefulness of prolonged wireless $\mathrm{pH}$ monitoring in patients with proton pump inhibitor 
refractory gastroesophageal reflux disease. J Neurogastroenterol Motil 2015;21:265-272.

27. Frazzoni M, de Bortoli N, Frazzoni L, et al. Impairment of chemical clearance and mucosal integrity distinguishes hypersensitive esophagus from functional heartburn. J Gastroenterol 2017;52:444-451.

28. Frazzoni M, de Bortoli N, Frazzoni L, et al. The added diagnostic value of postreflux swallow-induced peristaltic wave index and nocturnal baseline impedance in refractory reflux disease studied with on-therapy
impedance-pH monitoring. Neurogastroenterol Motil 2017;29:e12947.

29. Tobey NA, Carson JL, Alkiek RA, Orlando RC. Dilated intercellular spaces: a morphological feature of acid reflux--damaged human esophageal epithelium. Gastroenterology 1996;111:1200-1205.

30. Gao F, Gao Y, Chen X, Qian J, Zhang J. Comparison of esophageal function tests in Chinese patients with functional heartburn and reflux hypersensitivity. Gastroenterol Res Pract 2017;2017:3596148. 